\title{
Cell Biological Study on Abnormal Proteoglycan Synthesis in Vascular Cells Exposed to Heavy Metals
}

\author{
Yasuyuki Fujiwara* \\ Department of Environmental Health, Faculty of Pharmaceutical Sciences, Hokuriku University, Ho-3 Kanagawa-machi, Kanazawa \\ 920-1181, Japan
}

(Received January 28, 2004)

\begin{abstract}
Lead and cadmium are toxic heavy metals that have been shown to be possible risk factors of atherosclerosis in epidemiological and experimental studies. Since excess extracellular matrix, including proteoglycans, accumulates changing the composition and the structure in the atherosclerotic vascular wall, the effects of lead and cadmium on the proteoglycan synthesis in vascular cells have been studied using a cell culture system. The following results were obtained: Lead does not destroy endothelial cell layers but markedly inhibits the repair of the injured cell layers, which results from a lower response to endogenous basic fibroblast growth factor caused by inhibition of the synthesis of perlecan, a large heparan sulfate proteoglycan, in vascular endothelial cells. Lead selectively inhibits the synthesis of versican, a large chondroitin sulfate proteoglycan, in vascular smooth muscle cells only at a high cell density. Cadmium induces the synthesis of biglycan and decorin, small dermatan sulfate proteoglycans, in vascular smooth muscle cells only at a low cell density, while inhibiting the synthesis of other proteoglycan molecules. It is therefore suggested that lead and cadmium may influence the developmental process of atherosclerosis through disrupting the regulation of proteoglycan synthesis in vascular cells.
\end{abstract}

Key words — lead, cadmium, proteoglycan, vascular endothelial cell, vascular smooth muscle cell, atherosclerosis

\section{INTRODUCTION}

Atherosclerosis is a vascular lesion which is hypothesized to be initiated by dysfunction and injury of vascular endothelial cells followed by hyperplasia of vascular smooth muscle cells in the intima of vascular wall by a complicated mechanism. ${ }^{1)}$ Thus, the repair of damaged vascular endothelium without delay is important for prevention of atherosclerosis. Basic fibroblast growth factor (FGF-2) is crucially involved in endothelial repair through promotion of cell growth and migration in an autocrine fashion; the growth factor is leaked from severely damaged or dead endothelial cells and stimulates the cell proliferation near the damaged site. ${ }^{2}$ Heparin

\footnotetext{
*To whom correspondence should be addressed: Department of Environmental Health, Faculty of Pharmaceutical Sciences, Hokuriku University, Ho-3 Kanagawa-machi, Kanazawa 9201181, Japan. Tel.: +81-76-229-6189; Fax: +81-76-229-6208; Email: y-fujiwara@hokuriku-u.ac.jp
}

or heparan sulfate chains are required for both binding of FGF-2 to its cell surface receptor and exhibition of the biologic activites. ${ }^{3,4)}$ The glycosaminoglycans (GAGs) directly form the FGF-2 and FGF-receptor complexes and consequently the receptor dimmers; the ternary complex formation transduces the receptor tyrosine-kinase activation. ${ }^{5)}$ However, regulation of vascular endothelial cell proliferation by changes in GAG metabolism has been only incompletely understood.

Proteoglycans (PGs) are a heterogeneous group of proteins that have anionic GAG side chains such as heparan sulfate and chondroitin/dermatan sulfate covalently bound to core proteins as shown in Fig. $\left.1{ }^{6}\right)$ Vessel PGs are involved in the pathogenesis of vascular diseases as well as in the vascular properties of viscoelasticity, permeability, lipid metabolism, homeostasis, thrombosis, and matrix assembly. ${ }^{7)}$ Vascular endothelial cells express two subclasses of heparan sulfate PGs (HSPGs); one is the high $M_{\mathrm{r}}$ subclass which includes a large HSPG 


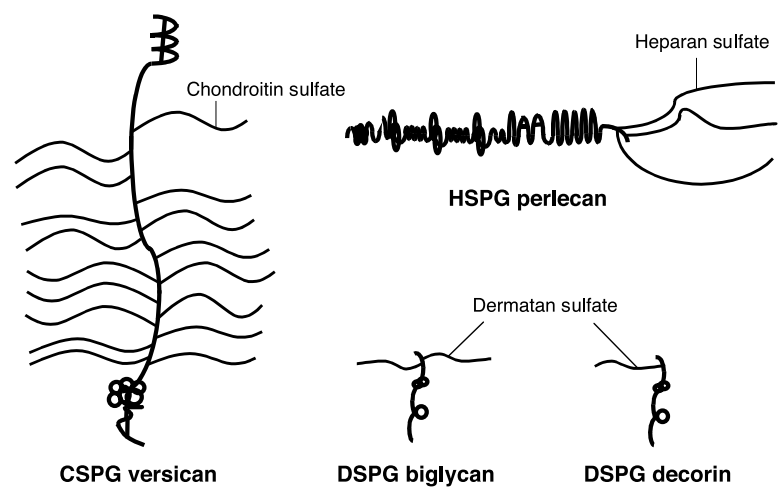

Fig. 1. Major Types of PGs Synthesized by Vascular Cells Major PGs synthesized by vascular cells are perlecan as a large HSPG, versican as a large CSPG, and biglycan and decorin as small leucine-rich DSPGs. Vascular endothelial cells mainly express perlecan and biglycan, and vascular smooth muscle cells express versican, biglycan and decorin with a low expression of perlecan.

perlecan $^{8)}$ and the other is the low $M_{\mathrm{r}}$ subclass which includes the small HSPGs syndecans and glypican. ${ }^{9)}$ Perlecan is the major product of HSPGs in the cells, ${ }^{10)}$ and markedly promotes the binding of FGF-2 to its cell surface FGF receptor, although other small HSPGs competitively act on this promotion. ${ }^{11,12)}$ Endothelial cells also constitutively synthesize a large chondroitin sulfate PG (CSPG) versican ${ }^{13)}$ and a small leucine-rich dermatan sulfate PG (DSPG) biglycan. ${ }^{14)}$ On the other hand, the major types of PGs synthesized by vascular smooth muscle cells are versican, ${ }^{15,16)}$ a small DSPG decorin and biglycan $^{14,17)}$ with a low expression of perlecan. ${ }^{8)}$

Epidemiological and experimental evidence suggests that exposure to environmental heavy metals such as lead and cadmium constitutes a risk factor for cardiovascular disease including atherosclerosis (Table 1) ${ }^{18-39)}$ Although there are numerous reports that show cardiovascular lesions induced by heavy metals, the majority of the reports are about the effects of lead and cadmium. Little is known, however, about the mechanisms by which lead and cadmium exhibit vascular toxicity at the cell molecular levels. Our laboratory has investigated the toxic effects of lead and cadmium on the physiological function of vascular cells. The results indicate that these metals induce various functional damages of both vascular endothelial and smooth muscle cells, including the proliferation and the secretion of fibrinolytic proteins. ${ }^{40-42)}$ The present report reviews our recent study on the abnormalities of vascular cell functions, including abnormal metabolism of PGs, induced by lead and cadmium.

\section{Toxic Effect of Lead on the Maintenance of Vas- cular Endothelial Monolayers}

The physiological maintenance of endothelial momolayers is important for prevention of atherosclerosis. Lead does not destroy endothelial monolayers ${ }^{43)}$ but strongly inhibited the repair of deendothelialized areas which had been artificially injured, when the repair was evaluated by morphological observation and the cell numbers appearing in the injured area. ${ }^{44)}$ It is speculated that lead disturbs the repair of endothelium damaged by hypertensive, environmental, nutritional and other factors. In fact, lead enhanced cadmium-induced a formation of de-endothelialized areas on the monolayers. ${ }^{43)}$ Since vascular endothelial cell proliferation is one of the most important events in the repair process of damaged endothelium, we next investigated the effect of lead on the proliferation of the cells. ${ }^{45)}$ The results show that lead markedly reduces the incorporation of $\left[{ }^{3} \mathrm{H}\right]$ thymidine into the acid-insoluble fraction of growing endothelial cells without nonspecific cell damage; other heavy metals including zinc, copper, manganese and nickel do not exhibit such an inhibition, indicating that lead is a unique metal that inhibits endothelial cell proliferation without nonspecific cell damage. In addition, lead inhibited the proliferation even when the cells were stimulated by exogenous FGF-2. Lead may disturb the repair process in endothelial cell layers which is promoted by FGF-2 leaked from severely damaged or dead cells at the damaged sites.

\section{Mechanism for Lead Inhibition of Vascular En- dothelial Cell Proliferation}

To address the question whether inhibition of endothelial cell proliferation by lead depends on endogenous FGF-2 or not, we investigated the response of growing endothelial cells to FGF-2 after exposure to lead. ${ }^{46)}$ In the presence of FGF-2 neutralizing antibody, lead failed to inhibit $\left[{ }^{3} \mathrm{H}\right]$ thymidine incorporation by the cells. The stimulation of the $\left[{ }^{3} \mathrm{H}\right]$ thymidine incorporation by exogenous FGF-2 was markedly reduced when the cells had been pretreated with lead. Taking these results together, it is suggested that the inhibitory effect of lead on endothelial cell proliferation may be due to a lower response of the cells to endogenous FGF-2. When the distribution of endogenous FGF-2 in the cell layer after exposure to lead was examined, the metal significantly reduced the amount of the growth factor bound to the cell surface HSPGs but not that bound to FGF-receptor and accumulated within the 
Table 1. Lead- and Cadmium-Induced Vascular Disorders

\begin{tabular}{|c|c|c|c|}
\hline Element & Reported by & & Vascular disorder \\
\hline \multirow[t]{11}{*}{ Lead } & Dingwall-Fordyce, I. and Lane, R. E. & 1963 & Cerebrovascular accident ${ }^{18)}$ \\
\hline & Revis, N. W. et al. & 1980 & Atherosclerosis ${ }^{19)}$ \\
\hline & Revis, N. W. et al. & 1981 & Atherosclerosis and hypertension ${ }^{20)}$ \\
\hline & Pirkle, J. L. et al. & 1985 & Hypertension ${ }^{21)}$ \\
\hline & Tomera, J. F. and Harakal, C. & 1986 & Vasoconstriction in vitro ${ }^{22)}$ \\
\hline & Perry, H. M. et al. & 1988 & Hypertension 23 ) \\
\hline & Lal, B. et al. & 1991 & Cardiotoxicity and hypertension ${ }^{24)}$ \\
\hline & Schwartz, J. & 1991 & Cardiovascular disease $^{25)}$ \\
\hline & Watts, S. W. et al. & 1995 & Vasoconstriction in vitro ${ }^{26)}$ \\
\hline & Houtman, J. P. & 1996 & Cardiovascular disease $^{27)}$ \\
\hline & Houston, D. K. and Johnson, M. A. & 1999 & Hypertension $^{28)}$ \\
\hline \multirow[t]{14}{*}{ Cadmium } & Perry, H. M., Jr. and Schroeder, H. A. & 1955 & Hypertension 29$)$ \\
\hline & Schroeder, H. A. and Vinton W. H., Jr. & 1962 & Hypertension ${ }^{30)}$ \\
\hline & Glauser, S. C. et al. & 1976 & Hypertension ${ }^{31)}$ \\
\hline & Revis, N. & 1978 & Hypertension ${ }^{32)}$ \\
\hline & Perry, H. M., Jr. et al. & 1979 & Hypertension ${ }^{33)}$ \\
\hline & Revis, N. W. et al. & 1980 & Atherosclerosis ${ }^{19)}$ \\
\hline & Revis, N. W. et al. & 1981 & Atherosclerosis and hypertension ${ }^{20)}$ \\
\hline & Niwa, A. and Suzuki, A. & 1982 & Hypertension ${ }^{34)}$ \\
\hline & Perry, H. M., Jr. et al. & 1983 & Hypertension ${ }^{35)}$ \\
\hline & Aalbers, T. G. and Houtman, J. P. & 1985 & Atherosclerosis ${ }^{36)}$ \\
\hline & Evans, D. H. and Weingarten, K. & 1990 & Vasoconstriction in vitro ${ }^{37)}$ \\
\hline & Subramanyam, G. et al. & 1992 & Atherosclerosis ${ }^{38)}$ \\
\hline & Houtman, J. P. & 1993 & Atherosclerosis ${ }^{39)}$ \\
\hline & Houtman, J. P. & 1996 & Cardiovascular disease $^{27)}$ \\
\hline
\end{tabular}

cells. Although lead slightly inhibited the direct binding of $\left[{ }^{125} \mathrm{I}\right] \mathrm{FGF}-2$ to cell surface HSPGs, the metal markedly suppresses the incorporation of $\left[{ }^{35} \mathrm{~S}\right]$ sulfate into heparan sulfate in the cell layer and the conditioned medium. In addition, the inhibition of $\left[{ }^{3} \mathrm{H}\right]$ thymidine incorporation by lead was completely restored by addition of heparin to the medium. It is therefore indicated that lead induces a lower response of vascular endothelial cells to FGF-2 through a strong inhibition of heparan sulfate synthesis rather than inhibition of the binding of FGF-2 to its cell surface receptor. In other words, the mechanism for lead inhibition of endothelial cell proliferation includes a reduction of the availability of endogenous FGF-2 through a lower ability of HSPGs to bind FGF-2 in the cell layers.

In order to clarify particular changes of HSPGs induced by lead, we next characterized HSPGs synthesized by growing endothelial cells after exposure to lead by biochemical techniques. ${ }^{47)}$ diethylaminoethyl (DEAE)-Sephacel ion exchange chromatography of $\left.{ }^{35} \mathrm{~S}\right]$ sulfate-labeled $\mathrm{PGs}$ revealed that lead markedly decreased the accumulation of HSPGs but not CS/DSPGs in the cell layer and the conditioned medium. When the HSPGs were separated on the basis of their hydrodynamic size by a Sepharose CL4B column, it was revealed that lead markedly reduced the radioactivity in the high $M_{\mathrm{r}}$ subclass rather than the low $M_{\mathrm{r}}$ subclass of HSPGs. In addition, Sepharose CL-6B chromatography of the large HSPGs showed that lead does not influence the length of their heparan sulfate chains. Analysis of core proteins labeled with ${ }^{35} \mathrm{~S}$-labeled amino acids by sodium dodecyl sulfate (SDS)-polyacrylamide gel electrophoresis indicated that lead markedly decreased the amount of a large HSPG core protein with a molecular mass of approximately $400 \mathrm{kDa}$. This core protein was identified as perlecan by Western blot analysis. It is thus suggested that the characteristic change of endothelial PGs after exposure to lead is a decrease in the number of perlecan molecules without a change in length of heparan sulfate chains. These findings suggest, then, that lead does not destroy endothelial cell layers but markedly inhibits the repair of the injured cell layers, which results from a lower response to endogenous FGF-2 

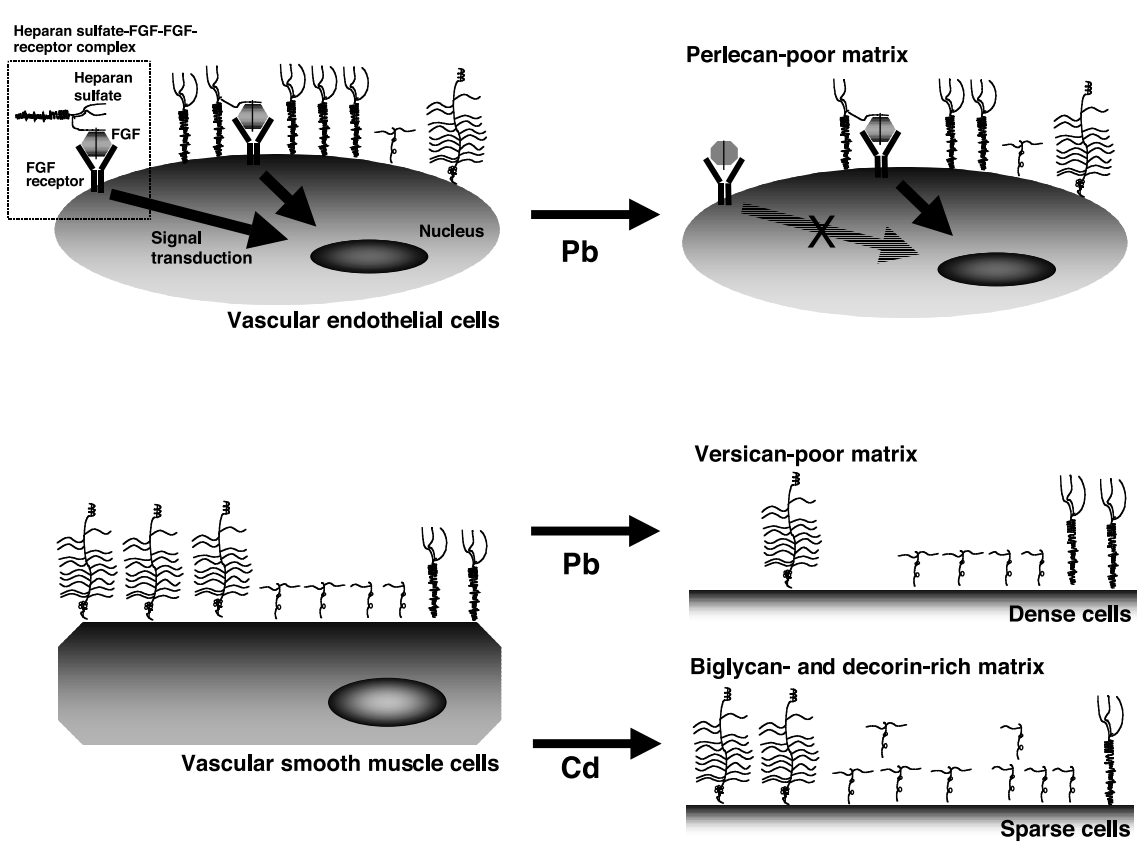

Fig. 2. A Possible Mechanism for Lead Inhibition of Vascular Endothelial Cell Proliferation (Upper Panel) and Lead- and CadmiumInduced Alterations of PGs in Extracellular Matrix of Vascular Smooth Muscle Cells (Lower Panel)

Lead strongly inhibits the synthesis of perlecan that promotes the binding of endogenous FGF-2 to the receptor in vascular endothelial cells. In vascular smooth muscle cells, lead selectively inhibits the synthesis of versican at a high cell density, whereas cadmium specifically induces that of biglycan and decorin at a low cell density.

caused by inhibition of perlecan synthesis in vascular endothelial cells (Fig. 2; upper panel).

\section{Effects of Lead on PG Synthesis of Vascular Smooth Muscle Cells}

Although endothelial cell perlecan contributes to the physiological maintenance of vascular endothelium through the regulation of FGF-2, other types of PGs, especially CS/DSPGs, accumulate and their composition variously changed in the atherosclerotic vascular wall; vascular smooth muscle cells are the cell type responsible for this accumulation and compositional change. ${ }^{48,49)}$ In the vascular wall, low density lipoprotein (LDL) is bound to GAG chains of $\mathrm{CS} / \mathrm{DSPGs},{ }^{50)}$ and the formation of LDL-PG complexes enhanced the accumulation of cholesteryl ester within macrophages present in atherosclerotic regions. ${ }^{51)}$ According to the response-to-retention hypothesis, the binding and retention of LDL by CS/ DSPGs of vascular smooth muscle cells are believed to be critical in the initiation of atherosclerosis. ${ }^{52)}$ CS/DSPGs such as versican, biglycan and decorin synthesized and secreted by vascular smooth muscle cells are generally implicated in the development and progression of atherosclerosis, whereas endothelial HSPG perlecan functions as a preventive factor for the disease.
To investigate the effect of lead on the formation of extracellular matrix in the vascular wall, we characterized PGs synthesized by dense cultures of vascular smooth muscle cells after exposure to the metal. ${ }^{53)}$ Lead significantly decreased the $\left[{ }^{35} \mathrm{~S}\right]$ sulfate incorporation into GAGs accumulated in the cell layer and the conditioned medium, indicating that the synthesis of GAGs is inhibited by the metal in vascular smooth muscle cells as well as endothelial cells. $\left.{ }^{35} \mathrm{~S}\right]$ Sulfate-labeled PGs were separated into three peaks on DEAE-Sephacel chromatography and only the peak with the highest charge density was markedly decreased by lead in both the cell layer and the medium. The highly charged PGs were eluted near the void volume on Sepharose CL-2B molecular sieve chromatography and were sensitive to chondroitin ABC lyase on Sepharose CL-6B chromatography, indicating that lead selectively inhibits the synthesis of large and highly charged CS/DSPGs rather than HSPGs. However, the length of chondroitin sulfate chains of the CS/DSPGs was unaffected by lead. On the other hand, analysis of core proteins labeled with ${ }^{35} \mathrm{~S}$-labeled amino acids by SDS-polyacrylamide gel electrophoresis showed that lead decreased the amount of a large CS/DSPG with a core protein of approximately $450 \mathrm{kDa}$; the core protein was identified as CSPG versican core by 
Western blot analysis. In addition, lead did not influence the fine structure of the chondroitin sulfate chains when the disaccharide units of the GAG chains were analyzed by fluorophore-assisted carbohydrate electrophoresis. ${ }^{54)}$ It is therefore suggested that lead inhibits the synthesis of the versican core protein in vascular smooth muscle cells without any change in chondroitin sulfate side chains. As a result, versican-poor extracellular matrix is induced by lead in vascular smooth muscle cells (Fig. 2; lower panel). The effect of lead on the PG synthesis in vascular smooth muscle cells is therefore completely different from that in vascular endothelial cells in which perlecan synthesis is selectively inhibited by the metal. Although the mechanism is unclear, it was clarified that lead disrupts the PG synthesis in vascular cells in a cell-type dependent manner.

\section{Effects of Cadmium on PG Synthesis of Vascular Smooth Muscle Cells}

To investigate whether the effect of lead on vascular smooth muscle cell PG synthesis is specific for lead or not, we determined the effect of cadmium on the PG synthesis. ${ }^{55)}$ Cadmium as well as lead is a possible risk factor for atherosclerosis. Sparse and dense cultures of the cells were metabolically labeled with $\left[{ }^{35} \mathrm{~S}\right]$ sulfate in the presence of cadmium at noncytotoxic levels. It was found that cadmium significantly decreased the incorporation of $\left[{ }^{35} \mathrm{~S}\right]$ sulfate into GAGs in both the cell layer and the conditioned medium in sparse cultures but not in dense cultures. $\left[{ }^{35} \mathrm{~S}\right]$ Sulfate-labeled PGs were separated into three peaks on DEAE-Sephacel chromatography, and the middle peak between low and highly charged PG peaks was markedly increased by cadmium in the cell layers of sparse vascular smooth muscle cells; however, no alteration was observed in dense cultures. Sepharose CL-4B molecular sieve chromatography and Sepharose CL-6B chromatography showed that the cadmium-induced PGs was small CS/DSPGs, and the hydrodynamic size and the length of the chondroitin/dermatan sulfate chains in the PGs were not changed by the metal. In addition, fluorophore-assisted carbohydrate electrophoresis analysis showed that cadmium did not change the sulfation pattern of disaccharides in chondroitin/ dermatan sulfate chains. ${ }^{54}$ The small CS/DSPGs were identified as biglycan and decorin by Western blot analysis. Furthermore, it was shown that cadmium raised the level of decorin core mRNA but not that of biglycan core mRNA when analyzed by reverse transcription polymerase chain reaction, suggesting that the metal stimulates the synthesis of biglycan and decorin at the post-transcriptional level including stabilization of the mRNA, and transcriptional level, respectively. However, cadmium decreased other cell layer-associated PGs that were separated from biglycan and decorin by DEAESephacel chromatography in the sparse cells; as a result, the overall amount of GAGs was decreased in both the cell layer and the conditioned medium. It is thus suggested that low levels of cadmium increase DSPGs, biglycan and decorin without any change in structure of dermatan sulfate chains in the extracellular matrix of vascular smooth muscle cells only when the cell density is low, whereas other cell layer-associated PGs, such as versican, were decreased by the metal (Fig. 2; lower panel). Although it is not certain whether lead and cadmium directly induce atherosclerosis in human vessels, these metals may be involved in the progression and formation of the vascular lesion through change in the composition of extracellular matrix, which includes PGs derived from vascular smooth muscle cells in the intima of vascular walls in different manners.

\section{CONCLUSION}

Regulation of PG synthesis is different between physiological and pathological conditions, and depends on the cell type and the cell density. Our results demonstrate that lead inhibits the repair of the injured cell layers, which results from a lower response to endogenous FGF-2 caused by inhibition of perlecan synthesis in vascular endothelial cells. They also show that lead selectively inhibits the synthesis of versican in vascular smooth muscle cells at a high cell density, whereas cadmium specifically induces that of biglycan and decorin at a low cell density. These observations reveal the effects of heavy metals on PG synthesis to be specific for each of them as well as cell-type and cell-density dependent. We propose that the pathogenesis of lead- and cadmium-induced atherosclerosis involves the abnormal PG metabolism in vascular cells. Abnormal metabolism of extracellular matrix in vascular cells by lead and cadmium is considered to be helpful for understanding the toxic effects of heavy metals in not only vascular tissue but also other tissues that are the targets of heavy metals. 
Acknowledgements The author is very grateful to Professor Toshiyuki Kaji of Hokuriku University for instruction and encouragement. This work was partly supported by the Specific Research Fund of Hokuriku University (to T. K. and to Y. F.) and by a Grant-in-Aid for Young Scientists (B) from Japan's Ministry of Education Culture, Sports, Science and Technology (to Y. F.).

\section{REFERENCES}

1) Ross, R. (1993) The pathogenesis of atherosclerosis: a perspective for the 1990s. Nature (London), 362, 801-809.

2) Sato, Y. and Rifkin, D. B. (1988) Autocrine activities of bovine basic fibroblast growth factor: regulation of endothelial cell movement, plasminogen activator synthesis, and DNA synthesis. J. Cell Biol., 107, 1199-1205.

3) Yayon, A., Klagsbrun, M., Esko, J. D., Leder, P. and Ornitz, D. M. (1991) Cell surface, heparin-like molecules are required for binding of basic fibroblast growth factor to its high affinity receptor. Cell, 64 , 841-848.

4) Ornitz, D. M., Yayon, A., Flanagan, J. G., Svahn, C. M., Levi, E. and Leder, P. (1992) Heparin is required for cell-free binding of basic fibroblast growth factor to a soluble receptor and for mitogenesis in whole cells. Mol. Cell. Biol., 12, 240-247.

5) Rusnati, M. and Presta, M. (1996) Interaction of angiogenic basic fibroblast growth factor with endothelial cell heparan sulfate proteoglycans. Biological implications in neovascularization. Int. J. Clin. Lab. Res., 26, 15-23.

6) Ruoslahti, E. (1988) Structure and biology of proteoglycans. Annu. Rev. Cell Biol., 4, 229-255.

7) Wight, T. N. (1980) Vessel proteoglycans and thrombogenesis. Prog. Hemost. Thromb., 5, 1-39.

8) Iozzo, R. V., Cohen, I. R., Grassel, S. and Murdoch, A. D. (1994) The biology of perlecan: the multifaceted heparan sulfate proteoglycan of basement membranes and pericellular matrices. Biochem. J., 302, 625-639.

9) Mertens, G., Cassiman, J. J., van den Berghe, H., Vermylen, J. and David, G. (1992) Cell surface heparan sulfate proteoglycans from human vascular endothelial cells: core protein characterization and antithrombin III binding properties. J. Biol. Chem., 267, 20435-20443.

10) Saku, T. and Furthmayr, H. (1989) Characterization of the major heparan sulfate proteoglycan secreted by bovine aortic endothelial cells in culture.
Homology to the large molecular weight molecule of basement membranes. J. Biol. Chem., 264, 35143523.

11) Aviezer, D., Hecht, D., Safran, M., Eisinger, M., David, G. and Yayon, A. (1994) Perlecan, basal lamina proteoglycan, promotes basic fibroblast growth factor-receptor binding, mitogenesis and angiogenesis. Cell, 79, 1005-1013.

12) Aviezer, D., Levy, E., Safran, M., Svahn, C., Buddecke, E., Schmidt, A., David, G., Vlodavsky, I. and Yayon, A. (1994) Differential structural requirements of heparin and heparan sulfate proteoglycans that promote binding of basic fibroblast growth factor to its receptor. J. Biol. Chem., 269, 117-121.

13) Morita, H., Takeuchi, T., Suzuki, S., Maeda, K., Yamada, K., Eguchi, G. and Kimata, K. (1990) Aortic endothelial cells synthesized a large chondroitin sulfate proteoglycan capable of binding to hyaluronate. Biochem. J., 265, 61-68.

14) Järveläinen, H. T., Kinsella, M. G., Wight, T. N. and Sandell, L. J. (1991) Differential expression of small chondroitin/dermatan sulfate proteoglycans, PG-I/ biglycan and PG-II/decorin, by vascular smooth muscle and endothelial cells in culture. J. Biol. Chem., 266, 23274-23281.

15) Schönherr, E., Järveläinen, H. T., Sandell, L. J. and Wight, T. N. (1991) Effects of platelet-derived growth factor and transforming growth factor-beta 1 on the synthesis of a large versican-like chondroitin sulfate proteoglycan by arterial smooth muscle cells. J. Biol. Chem., 266, 17640-17647.

16) Yao, L. Y., Moody, C., Schönherr, E., Wight, T. N. and Sandell, L. J. (1994) Identification of the proteoglycan versican in aorta and smooth muscle cells by DNA sequence analysis, in situ hybridization and immunohistochemistry. Matrix Biol., 14, 213225.

17) Schönherr, E., Järveläinen, H. T., Kinsella, M. G., Sandell, L. J. and Wight, T. N. (1993) Plateletderived growth factor and transforming growth factor- $\beta 1$ differentially affect the synthesis of biglycan and decorin by monkey arterial smooth muscle cells. Arterioscler. Thromb., 12, 1026-1036.

18) Dingwall-Fordyce, I. and Lane, R. E. (1963) A follow-up study of lead workers. Br. J. Ind. Med., 20, 313-315.

19) Revis, N. W., Major, T. C. and Horton, C. Y. (1980) The effects of calcium, magnesium, lead, or cadmium on lipoprotein metabolism and atherosclerosis in the pigeon. J. Environ. Pathol. Toxicol., 4, 293-303.

20) Revis, N. W., Zinsmeister, A. R. and Bull, R. (1981) Atherosclerosis and hypertension induced by lead 
and cadmium ions: an effect prevented by calcium ion. Proc. Natl. Acad. Sci. U.S.A., 78, 6494-6498.

21) Pirkle, J. L., Schwartz, J., Landis, J. R. and Harlan, W. R. (1985) The relationship between blood lead levels and blood pressure and its cardiovascular risk implications. Am. J. Epidemiol., 121, 246-258.

22) Tomera, J. F. and Harakal, C. (1986) Mercury- and lead-induced contraction of aortic smooth muscle in vitro. Arch. Int. Pharmacodyn. Ther., 283, 295302.

23) Perry, H. M., Jr., Erlanger, M. W. and Perry, E. F. (1988) Increase in the blood pressure of rats chronically fed low levels of lead. Environ. Health Perspect., 78, 107-111.

24) Lal, B., Murthy, R. C., Anand, M., Chandra, S. V., Kumar, R., Tripathi, O. and Srimal, R. C. (1991) Cardiotoxicity and hypertension in rats after oral lead exposure. Drug Chem. Toxicol., 14, 305-318.

25) Schwartz, J. (1991) Lead, blood pressure, and cardiovascular disease in men and women. Environ. Health Perspect., 91, 71-75.

26) Watts, S. W., Chai, S. and Webb, R. C. (1995) Lead acetate-induced contraction in rabbit mesenteric artery: interaction with calcium and protein kinase C. Toxicology, 99, 55-65.

27) Houtman, J. P. (1996) Trace elements and cardiovascular diseases. J. Cardiovasc. Risk, 3, 18-25.

28) Houston, D. K. and Johnson, M. A. (1999) Lead as a risk factor for hypertension in women. Nutr. Rev., 57, 277-279.

29) Perry, H. M., Jr. and Schroeder, H. A. (1955) Concentration of trace metals in urine of treated and untreated hypertensive patients compared with normal subjects. J. Lab. Clin. Med., 46, 936.

30) Schroeder, H. A. and Vinton, W. H., Jr. (1962) Hypertension induced in rats by small doses of cadmium. Am. J. Physiol. 202, 515-518.

31) Glauser, S. C., Bello, C. T. and Glauser, E. M. (1976) Blood-cadmium levels in normotensive and untreated hypertensive humans. Lancet, 1, 717-718.

32) Revis, N. (1978) A possible mechanism for cadmium-induced hypertension in rats. Life Sci., 22, 479-487.

33) Perry, H. M., Erlanger M. and Perry, E. F. (1979) Increase in the systolic pressure of rats chronically fed cadmium. Environ. Health Perspect., 28, 251260.

34) Niwa, A. and Suzuki, A. (1982) Effects of cadmium on the tension of isolated rat aorta (a possible mechanism for cadmium-induced hypertension). $J$. Toxicol. Sci., 7, 51-60.

35) Perry, H. M., Jr., Erlanger, M. W. and Perry, E. F. (1983) Effect of a second metal on cadmium-induced hypertension. Arch. Environ. Health, 38, 80-85.
36) Aalbers, T. G. and Houtman, J. P. (1985) Relationships between trace elements and atherosclerosis. Sci. Total Environ., 43, 255-283.

37) Evans, D. H. and Weingarten, K. (1990) The effect of cadmium and other metals on vascular smooth muscle of the dogfish shark, Squalus acanthias. Toxicology, 61, 275-281.

38) Subramanyam, G., Bhaskar, M. and Govindappa, S. (1992) The role of cadmium induction of atherosclerosis in rabbits. Indian Heart J., 44, 177-180.

39) Houtman, J. P. (1993) Prolonged low-level cadmium intake and atherosclerosis. Sci. Total Environ., 138, 31-36.

40) Kaji, T. (2004) Cell biology of heavy metal toxicity in vascular tissue. Yakugaku Zasshi, 124, 113-120.

41) Yamamoto, C. (2000) Toxicity of cadmium and lead on vascular cells that regulate fibrinolysis. Yakugaku Zasshi, 120, 463-473.

42) Fujiwara, Y. and Kaji, T. (2000) Inhibition of the repair of injured endothelial cell monolayers by lead and its possible mechanisms. J. Health Sci., 46, 14.

43) Kaji, T., Suzuki, M., Yamamoto, C., Mishima, A., Sakamoto, M. and Kozuka, H. (1995) Severe damage of cultured vascular endothelial cell monolayer after simultaneous exposure to cadmium and lead. Arch. Environ. Contam. Toxicol., 28, 168-172.

44) Fujiwara, Y., Kaji, T., Sakurai, S., Sakamoto, M. and Kozuka, H. (1997) Inhibitory effect of lead on the repair of wounded monolayers of cultured vascular endothelial cells. Toxicology, 117, 193-198.

45) Kaji, T., Fujiwara, Y., Hoshino, M., Yamamoto, C., Sakamoto, M. and Kozuka, H. (1995) Inhibitory effect of lead on the proliferation of cultured vascular endothelial cells. Toxicology, 95, 87-92.

46) Fujiwara, Y. and Kaji, T. (1999) Possible mechanism for lead inhibition of vascular endothelial cell proliferation: a lower response to basic fibroblast growth factor through inhibition of heparan sulfate synthesis. Toxicology, 133, 147-157.

47) Fujiwara, Y. and Kaji, T. (1999) Lead inhibits the core protein synthesis of a large heparan sulfate proteoglycan perlecan by proliferating vascular endothelial cells in culture. Toxicology, 133, 159169.

48) Gutierrez, P., O’Brien, K. D., Ferguson, M., Nikkari, S. T., Alpers, C. E. and Wight, T. N. (1997) Differences in the distribution of versican, decorin, and biglycan in atherosclerotic human coronary arteries. Cardiovasc. Pathol., 6, 271-278.

49) Shirk, R. A., Parthasarathy, N., San Antonio, J. D., Church, F. C. and Wagner, W. D. (2000) Altered dermatan sulfate structure and reduced heparin cofactor II-stimulating activity of biglycan and 
decorin from human atherosclerotic plaque. J. Biol. Chem., 275, 18085-18092.

50) Camejo, G., Acquatella, H. and Lalaguna, F. (1980) The interaction of low density lipoproteins with arterial proteoglycans. An additional risk factor? Atherosclerosis, 36, 55-65.

51) Salisbury, B. G., Falcone, D. J. and Minick, C. R. (1985) Insoluble low-density lipoproteinproteoglycan complexes enhance cholesteryl ester accumulation in macrophages. Am.J. Pathol., 120, 6-11.

52) Williams, K. J. and Tabas, I. (1995) The responseto-retention hypothesis of early atherogenesis. Arterioscler. Thromb. Vasc. Biol., 15, 551-561.

53) Fujiwara, Y., Yamamoto, C. and Kaji, T. (2000) Proteoglycans synthesized by cultured bovine aortic smooth muscle cells after exposure to lead: lead selectively inhibits the synthesis of versican, a large chondroitin sulfate proteoglycan. Toxicology, 154, 9-19.

54) Fujiwara, Y., Yamamoto, C., Kaji, T. and Plaas, A. H. (2003) Analysis of chondroitin/dermatan sulfate microstructure in cultured vascular smooth muscle cells after exposure to lead and cadmium. J. Health Sci., 49, 534-540.

55) Fujiwara, Y., Tsumura, N., Yamamoto, C. and Kaji, T. (2002) Different effects of cadmium on proteoglycan synthesis of arterial smooth muscle cells: increase in small dermatan sulfate proteoglycans, biglycan and decorin, in the extracellular matrix at low cell density. Toxicology, 170, 89-101. 